\title{
2
}

\section{Internet support to school innovation management}

\author{
B.Z. Barta \\ Ministry of Education \\ Jerusalem, Israel,51 Disraeli Str. Haifa 34333, Israel. \\ Phone: (972)-4-8345845 \\ e-mail:ben@actcom.co.il

\section{Telem} \\ School of Education, Tel-Aviv University, Tel-Aviv, Israel \\ Phone: (972)-3-6407123 Fax: (972)-3-6409477, \\ e-mail: telem@post.tau.ac.il
}

\begin{abstract}
Internet services that support the introduction of innovations in teaching and management in the educational system are: access to global information resources, communication among peer-teams and improved communication links between individuals and team members. Internet's support for teaching, management and supervision is elaborated. A pilot project in Israel presently involving five user groups, including curriculum developers and supervisors, working in the field of Informatics and Information Technologies is presented. Preliminary recommendations are formulated.
\end{abstract}

\section{Keywords}

Educational management, professional development, curriculum development, internet, user groups, teleconferencing

\section{INTRODUCTION}

In recent years, Internet has developed into a reliable, accessible, large-scale communication medium. Various educational initiatives use its services to support a variety of activities (Johnson, 1995; Hughes, 1993; Protheroe and Wilson, 1994; West, 1993). However, only few publications refer to Internet applications supporting curricular development and innovation, implementation of new curricula and approaches (Doyle, 1995; Hert, 1994; Seguin, 1994).

Schools are loosely coupled organizations (Weick 1976, 1982). As a result the information flow among a school's functionaries and between it and other schools is 
very often slow or even hardly exists at all. In the case of innovation projects, very often in a given school only a few teachers and their subject coordinators are involved in the project, and they work on identical or similar issues and deal with similar problems. Other teams in other schools, though geographically apart, also deal with similar issues and face similar problems. The groups at the different schools do not cooperate due to communication difficulties, thus impending exchange of ideas and accumulation of experience.

Updated and accessible information, including effective tools for easy information retrieval and exchange of ideas, constitute a fundamental requirement for a variety of activities related to education in general and teaching in particular. This is especially so as regards innovative activities leading to school change and renewal (Telem, 1990a). Efficient communication is extremely important for dealing with implementation of educational innovation, which usually involves one or several development teams, as well as implementation teams who are variously located. The importance of effective communication grows with the size of the project (e.g., number and size of teams involved).

The project described in this paper is at a very early stage of development. It is intended to investigate the use of Internet in supporting curricular innovation. As a byproduct, the project also considers Internet contribution to school employees' routine work and educational staff in-service development.

\section{THE RATIONALE OF THE INTERNET PROJECT}

The Israeli school system is a rather dynamic one, with respect to curricular and methodological changes and updates. Specifically, in the field of Information Technology and Informatics, significant innovations have been continuously fostered during recent years (Gal-Ezer et al., 1995; Telem and Barta 1993; Barta and Telem, 1992, Barta 1990).

While curricular development projects deal with a variety of subjects, a common line of activity typifies most of them. Each project is composed of several stages, each one with its particular communications needs and "classical" communication means (e.g., meetings, telephone). The Internet may constitute a powerful additional communication component to these means, in each of the following main stages:

Design and planning. The main communication needs at this stage relate to the gathering of information on similar work done or being carried out by other teams and, perhaps, setting-up contacts and cooperation with them. Classical communication means for this stage are libraries with their abstracts data bases (e.g., ERIC), published journals, correspondence by mail or fax, telephone, personal visits and/or meetings.

Internet may contribute to this stage by the search and "surfing" tools provided by the World Wide Web (WWW) and by electronic-mail (e-mail) services. The WWW system may help in gathering updated information much faster and easier than any of the above mentioned means. The e-mail facility may provide means for team-to-team information exchange, preferable to ordinary mail or fax because of its ease of access and use, speed, cost, accuracy of data transfer and the variety of the types of information that can be transferred (texts, graphics, computer files).

Development and small scale implementation and evaluation. This stage is usually achieved by a small team who can get together and who communicate mainly in meetings, through brainstorming and through the direct transfer of documents. Internet may make only a minor contribution at this stage.

Partial implementation and evaluation. At this stage a larger group of people is involved. For instance, development team members and teachers in different schools spread out over several regions, and they all implement the new curriculum in their classrooms. Distribution of learning materials and aids, support and advice provided by 
the developers to the implementors, feedback from the implementors and collection of data for ongoing evaluation, are the major communications-based activities at this stage of development. The classical means of communication at this stage, consist of regular pre-scheduled group meetings, in-service training and seminars (development team with teachers), visits of development team members to the participating schools, peer-topeer contacts at meetings and by phone, transfer of documents (by mail, fax or diskettes), ad-hoc solving of problems that occur during implementation - mainly by telephonic contacts.

In addition to the above mentioned classical means, Internet constitutes a valuable tool for achieving the project's communication needs at this stage. The main goal of the project described in this paper is to develop and make available the additional Internet communication tools needed at this stage, such as information exchange and discussions between groups of people without forcing teams and team members to be present at the same place (e.g., scheduled meetings) at the same time (e.g., telephone, videoconferencing); transfer of messages, documents and files; on-line access to information banks containing well organized items relevant to the group. Emphasis is on approaching large groups of people, on dealing with large amounts of information in an efficient and cost effective way, and on efficient methods used to update, modify, transfer, search and retrieve information.

Full scale implementation. This stage involves hundreds of teachers, members of the development teams and teams of supervisors and advisors. At the end of this stage the innovation changes into routine. At this stage, the information in information banks is less dynamic (i.e., changes are less frequent and of a minor nature) but the size of the group using them and requiring communication facilities grows significantly. Coordination issues may have an important role (e.g., within the supervising team, between the supervising and the development teams).

Internet may play the same roles as in the partial implementation stage, the main change being the size of the group using the services.

\section{Summing up, the main goals of the Internet project are:}

- Definition of Internet services and applications that are valuable to curricular innovation in each stage of a project.

- Identification of problems and difficulties to be overcome in order to assimilate and support the services, as defined.

- Development of the specific Internet application and its operation and maintainence, both technically and content wise.

- Establishment of an evaluation mechanism that will provide ongoing feedback needed for introducing changes and improvements both to the new curricula and to the use of the Internet services.

\section{INTERNET SERVICES - SUPPORT TO INNOVATION}

A good overview of Internet's potential contribution to education and educational management is presented by Fung and Pun (1996). The following, Internet-based services have been considered suitable for satisfying the requirements mentioned in Section 2: 


\subsection{Global Communication Services}

"Reinventing the Wheel", i.e., repetition of achievements (or mistakes) already made by others, may hinder the development and implementation of innovative educational projects and research. "Bridging" between members of the development team, between the intraschool and interschool information "islands", and between the school and the other levels of the educational systems, constitutes a challenge faced by the educational system (Telem, 1990b). Internet's networks of live, active interest-groups, may help in this bridging process. Internet allows direct and iteractive contact with colleagues and teams dealing with similar issues. It enables users to actively participate in live discussion groups, i.e., it makes possible inter-team cooperation. The use of these tools in educational settings may be of crucial importance at international, national and regional levels.

\subsection{Link to Global Information Resources}

Internet's on-line availability of relevant and significant information and its search, browsing and retrieval tools provide easy access to local and international educational library catalogues and databases.

\subsection{Support to Educational Innovation}

Implementation and success of new curricula, teaching methods and approaches, very often depend, among other factors, on a sound infrastructure of information exchange. Promising ideas and means may fail when not effectively conveyed, brainstormed and supported. A curriculum development team may use Internet as an effective tool for distributing its thesaurus of resources, for an on-going updating of teaching materials, syllabi, bibliography and sources of information relevant to the subject matter. It may also present and/or explain didactics, strategies, doubts and difficulties, as well as onsite innovations related to the teaching process. Problems, exercises with their solutions, teaching materials, graphics, demonstrations and multimedia are available through the Internet. Moreover information and resources can be organized by using multiple links among the information items by hypertext techniques, which provide tools for access and selection unique to the computerized media. Internet's down-loading and up-loading capability enable fast transfer of information among users. Internet enhances active human communications, ideas transfer, feedback, discussion and elaboration. However, it requires written - though not too formal - communication, which is slower and, from some aspects, less convenient than speaking (as long as voice transfer will not be used on a large scale).

Internet facilitates several communication modes, each of them with its rationale for innovation support. The one-to-many mode is the most common mode for conveying information from a development team to the groups of teachers implementing the new curriculum. Similarly, Internet provides a path from any group member to each of the other group members. Thus, the one-to-many mode can easily be used also in a manyto-many mode - when all members of the group are allowed to provide input and make it available to the entire group. The many-to-many mode allows group discussions when all members refer to a specific issue, raised by any member of the group, including its leader/s. This may take the shape of a synchronous process ("chat"), when all participants provide their inputs and receive others' inputs - all together at the same time. Or, it may be asynchronous - when each member accesses the system at any convenient time, reads the other group members' inputs and provides his/her own. The one-to-one mode provides a personal, confidential communication link between any two persons, specifically between peers, members of the group, or between the leader and group 
members. The many-to-one mode is effective for data collection and for answering a specific individual query.

When innovation is the issue, Internet's services and its information infrastructure may be of crucial importance for its success. This in addition to its similar valuable support to routine teaching and educational activities, Internet can provide similar services to both innovative and routine work of managers and supervisors. Managers and supervisors may use Internet tools for helping them to manage, communicate, supervise and advise their peers, subordinates and superiors. For example, the principal can use Internet to improve information exchange and communication between her/himself and various school employees and school management teams (e.g., deputyprincipals, councelors, subject-coordinators). The Internet may support her/him, in communicating with his/her peers (i.e., other principals) and with various employees in the school district and central educational authorities. School districts and central educational authorities can use Internet services in similar ways.

\section{A PILOT PROJECT: THE ISRAELI INFORMATICS TEACHERS' NET}

In line with the general approach presented in Section 3, the Israeli Ministry of Education established during 1995/6 school year an Informatics teachers' Internet service. Its target population is Informatics and Information Technologies (IT) teachers, supervisors and curriculum development teams. The establishment of the net is considered as a pilot project, starting with a few scores of teachers and other functionaries, which will hopefully develop to cover several hundreds in the next school-year, and finally, about 2000 participants, i.e., the entire community of Informatics teachers and related team-members in Israel.

Priority was given to teachers who are implementing new curricula and new approaches, with the aim that the net should support this innovation process. A group teaching the regular curricula and all supervisors and advisors related to Informatics teaching were also included.

\subsection{Basic Services on the Net}

Currently, the net provides the following basic types of services:

Personal Mail is ordinary e-mail allowing exchange of messages between users on the net, including forwarding the same message to several/all users.

Bulletin Boards contain current information provided by a user and addressed to a defined group of users, who subscribe to a specific board. Each bulletin board has a leader, in charge of the board's activity. The board can be either moderated or unmoderated. The leader of a moderated bulletin board is responsible for its contents. The board will contain information provided only by him/her or by a member of the group as approved by the leader. The leader has the sole right to write and/or remove information from the moderated board. An unmoderated board contains information posted freely by any of its subscribing users - i.e., the initial information or message as provided by its initiator and group members' reactions. Still, the leader is responsible for looking after the activity on the board, and in extreme cases s/he may restrict or even remove information posted.

Discussion Groups are in fact unmoderated bulletin boards dedicated to a specific subject/s that a group of users is concerned about. It contains all the exchanged messages, relevant to the selected subject/s.

Information Banks contain large amounts of well structured and organized information. Access to the information banks is possible in a hierarchical way using adequate menus, by hypertext techniques using multiple links between files and a variety 
of key-word search techniques. The information banks are created, augmented and updated by teams of experts in a specific subject-matter. An information bank coordinator is in charge of the updateness of the data. Information banks are not replaced very frequently. Appreciable effort is invested to adequately design, establish and update them. In many cases information initially published in a bulletin board is later included in the information bank.

Information banks are either general, i.e., used by the whole community of users on the net, or specific to some group of users. Existing information banks, still under construction include: syllabi, bibliography, didactic advice, learning materials, problems and exercises, hints and tips, and general instructions related to the organization and contents of teaching. Access to existing national and international information banks is available with adequate guidance.

News Bulletins. The net provides several news bulletins, implemented as moderated bulleting boards: A monthly "Newspaper", reviewing main news and current developments in Informatics and IT - i.e., software, hardware, applications. The "newspaper" is based on professional journals and IT industry announcements, and provides references to those wishing to read the entire article rather than its abstract. Its main goals are to convey important and updated information to the teaching community. The "System News" and "General Information" are additional news bulletins for announcements which are of interest to all users on the net.

\subsection{Groups on the Net}

The following five user groups are presently active on the pilot net. Each of them uses e-mail services and both moderated and unmoderated bulletin boards. Each group on the net has its own specific information bank. As the activity of each group goes on, it produces new items to be added to the information bank.

Software Design: A group of Informatics teachers implementing a new curriculum in advanced Informatics in 12th grade. The curriculum was developed by a team of experts at the Hebrew University in Jerusalem. There are some 20 teachers in the group, located in different parts of Israel.

Computer and Communications Literacy: A group of teachers teaching the subject at junior high school level, organized as a didactic workshop with Internet communication support. The group deals mainly with didactic problems pertaining to the development of adequate learning materials and approaches. Each member develops materials and transfers them for trial and comments to the other group members. The final product consists of modules of educational materials available to any interested teacher. The group is moderated by a supervisor at the Ministry of Education.

Logic Programming in Prolog: This is one of the modules of the introductory part in the Informatics curricula. It was developed by a team of experts of the Weizman Institute of Science in Rehovot and was released for general use towards the 1996/7 school year.

Southern Group: A group of teachers in south Israel, all related to one supervisoradvisor who acts as the group moderator. In contrast to the formerly mentioned subjectoriented groups, this group includes teachers of any subject within the broad field of Informatics and IT. This group was formed with the intention to investigate the help that can be provided by Internet to the work of a member of a supervising team.

Supervisors' Group: All its members are supervisors/advisors active within the Ministry of Education and dealing with teaching of Information and IT. The group is moderated by one of the supervisors, having a central position within the group's activities. It supports all information exchange required to support the activity of this group. 


\section{CONCLUSION}

Though the pilot project is in its initial stage, it is apparent that a well functioning and information-rich system provides a valuable tool to support the managerial, educational and instructional activities in the educational system, both for innovative activities and routine work. However, some recommendation can be clearly formulated:

- The system has to be reliable and accessible. If it is not, users will not access it.

- Appreciable effort is needed to set up an information bank of attractive size and contents, well formatted for easy and convenient access.

- Good information banks and a good news service do attract users to access the system and they then try its communications services as well.

- It takes time and effort to convince people to use the net. It seems to be hard to get used to a new tool. The groups' leaders have to find means to promote the system and encourage its users, until a critical mass of contents and users is reached.

\section{REFERENCES}

Barta, B.Z. (1990) End users education at high school level: a preliminary report. Education and Computing, 6(1, 2), 63-68.

Barta, B.Z. and Telem, M. (1992) New trends within the basic training of I.T. professionals in Israel, in Professional Development of Information Technology Professionals (eds. B.Z. Barta et al.), North-Holland, Amsterdam.

Doyle, S.C. (1995) Telementoring takes off in California: the Telemation project develops integrated curriculum. Internet Research, 5 (1), 40-45.

Fung, A.C.W. and Pun, S.W. (1996) The impact of Internet on ITEM: educational management in preparation for the future, in Proceedings of the 2nd IFIP International Working Conference on ITEM, Hong Kong Baptist University, Hong Kong.

Gal-Ezer, J., Beeri, C., Harel, D. and Yehudai, A. (1995) A high school program in computer science. Computer, 28(10), 73-80.

Hert, A.C. (1994) A learning organization perspective on training: critical success factors for Internet implementation. Internet Research, 4(3), 36-44.

Hughes, R.D. (1993) Appropriate and distributed networks: a model for K-12 educational telecommunications. Internet Research, 3(4), 22-29.

Johnson, A.D. (1995) The Mankato schools Internet project. Internet Research, 5(1), 40-45.

Protheroe, N. and Wilson, E. (1994) The Internet handbook for school users. Educational research services, Arlington, VA.

Seguin, A. (1994) Using the Internet in professional development. Paper presented at the American Vocational Association Convention, Dallas.

Telem, M. (1990a) DSS in educational organizations, Computers and Educations, 14 (1), 61-69.

Telem, M. (1990b) Educational DSS: Potential services, benefits, difficulties, and dangers. Computers and Educations, 14 (1), 71-80.

Telem, M. and Barta, B.Z. (1993) Case tools in the basic training of I.T. professionals in Israeli high schools, in Software Engineering Education (eds. B.Z. Barta et al.), North-Holland, Amsterdam, 263-272.

Weick, K.E. (1976) Educational organizations as loosely coupled systems. Administrative Science Quarterly, 21(1), 1-19. 
Weick, K.E. (1982) Administering education in loosely coupled schools. Phi Delta Kappan, 63, (673-76)

West, P. (1993) The mother of all networks. Teacher Magazine, 4 (4), 19-22.

\section{BIOGRAPHIES}

Ben-Zion Barta, Ph.D. from Technion Israel, Chief Inspector for Computers in Education in the Ministry of Education, Israel, in charge of the coordination of R\&D projects and the implementation of computer education activities in the Israeli school system. Chaired IFIP's Working Group on Training and Education of IT Professionals. Chaired several Working Conferences, published and edited in the areas of Informatics' teaching and of computers in education.

Moshe Telem, Chair of the educational administration program in the School of Education, Tel-Aviv University, received his doctorate from the Hebrew University in Jerusalem. He specializes in MIS in education and educational administration. $\mathrm{He}$ has published widely on a variety of computerized educational issues. 